\title{
PREVALENCE OF ORAL WHITE LESIONS IN PATIENTS WITH END-STAGE RENAL DISEASE: A CROSS SECTIONAL STUDY
}

\author{
Asmaa Abou-Bakr *, Ashraf Talaat ${ }^{* *}$ and Amira M Abdelazim ${ }^{* * *}$
}

\begin{abstract}
Introduction: End stage renal disease (ESRD) has accompanying oral pathologies that emerge from the disease process or from the impact of hemodialysis or both. Inevitably, untreated oral lesions may aggravate clinical presentation and prognosis of renal disease. The aim of our study was to investigate the clinical patterns of white lesions in the oral cavity in the patients having endstage renal disease, and to study the factors associated with the appearance of these lesions.
\end{abstract}

Methods: A cross-sectional, descriptive and observational study was designed to determine prevalence of oral white lesions among patients with ESRD attending the nephrology hemodialysis department for more than six months at Qalyub Hospital in Qalyub, Al Qalyubia Governorate, Egypt. A total of 114 adult participants of both genders from 30 up to 60 years were included in the study. A salivary $\mathrm{pH}$ and salivary flow rate were estimated.

Results: Oral white lesions were found among 33 patients out of 114 with a prevalence of $28.9 \%$ in the studied sample of ESRD patients. The most common oral white lesions were oral candidiasis (11.4\%), Lichen planus or lichenoid reaction lesions (10.5\%) and oral keratotic lesions $(6.1 \%)$, while the least oral white lesions were Leukoplakia (2.6\%) and uremic stomatitis $(2.6 \%)$.

Conclusion: An association between the prevalence of oral candidiasis and the following (salivary $\mathrm{pH}$, salivary flow rate) was found. Also an association between uremic stomatitis and the higher blood urea and higher serum creatinine level was found in our studied sample of the patients with ESRD.

KEYWORDS: Renal, lichenoid, candidiasis, hemodialysis.

\section{INTRODUCTION}

In chronic kidney disease (CKD), patient can remain symptom free for a while; this may be attributed to the residual renal functions and also to the compliance in the glomerular filtration rate. While the renal disease advances, the patient pass through 5 stages of disease progression to end in bilateral renal destruction that is definitely

\footnotetext{
* Assistant Lecturer at Department of Oral Medicine and Periodontology, Faculty of Dentistry, British University, Cairo, Egypt. - Phd Candidate at Department of Oral medicine, Faculty of Dentistry, Ain Shams University, Cairo, Egypt.

** Head of Internal Medicine Department, Faculty of Medicine, Benha University, Cairo, Egypt.

*** Associate Professor of Oral Medicine and Periodontology, Faculty of Dentistry, Cairo University, Egypt.
} 
irreversible and is accompanied by a high morbidity rates. Furthermore, it is rich in symptoms explained by many organs and organ-system impacts. The oral cavity is consequently impacted as many other organs and systems (Belazelkovska et al., 2013).

Many respiratory, endocrinal and immunological complications emerge as sequelae of both the disease itself and therapy. These complications are likely to involve the oral cavity. Moreover, multiple studies declared that the incidence of many oral pathological conditions is a way high in renal patients on maintenance dialysis (Kao et al., 2000; Rahmati et al., 2002; Proctor et al., 2005).

Renal patients on maintenance hemodialysis (HD) are more prone to infections, attributed mainly to the generalized debilitation status, impaired immune response in addition to persistent chronic inflammation. The oral inflammation might be more intense as a result of the main illness combined by infection (Rodakowska et al., 2018).

A variety of lesions in oral mucosa has been reported in renal dialysis patients and kidney transplant; such lesions are secondary to either drug therapy or immune-suppressive drugs. Lesions vary between white, red patches, nodular, macular and / or ulcerative lesions, lichen-planus like lesions, oral hairy leukoplakia, and lesions histo-pathologically identical to Epstein-Barr virus, non-Hodgkin's lymphoma and/or Kaposi's sarcoma.

As the oral cavity is exposed to the external environment, it is susceptible to an immense amount of environmental harms (Ship et al., 2003). Among the common findings in the oral cavity are white lesions. The abnormal keratin usually reflects light spectrum equally and hence lesion appears white. In addition, saliva is continually bathing hyperkeratotic intra-oral tissues similar to prolonged immersion of palms and soles in water (Payne, 1975; Tong and Ferguson, 2002). Plenty of white lesions are commonly categorized as 'Leukoplakia'; which accurately denotes a 'white plaque' and was first mentioned by Schwimmer in 1877 likely to report a syphilitic glossitis lesion (Cooke, 1975).

\section{SUBJECTS AND METHODS}

A cross-sectional, descriptive and observational study with 114 ESRD patients was designed to determine prevalence of oral white lesions among patients attending the Nephrology Hemodialysis department for more than three months at Qalyub Hospital in Qalyub, Al Qalyubia Governorate, Egypt. The inclusion criteria were: adult participants of both genders, their ages ranged from 30 up to 60 years, patients were at least for 6 months up to 2 years on renal hemodialysis, and frequency of dialysis was twice per week and duration of 3 hours per session.

All included patients had confirmed diagnosis of end-stage renal failure regardless of the etiology of the condition. The exclusion criteria were: patients with the history of malignancy or kidney transplants, vulnerable groups such as pregnant females, prisoners, mentally and physically handicapped individuals, and those on chemotherapy or radiotherapy. The proposal was reviewed by the Faculty of Dentistry, Ain Shams University Research Ethics Committee (FDASU-REC).

Patients who met the eligibility criteria were subjected to comprehensive oral assessment using a designed chart adapted from the World Health Organization oral health assessment form for adults, 2013 and scored (OHS WHO 2013). The edentulous patients were asked to remove their denture(s) (if any) to examine the underlying tissues more accurately. Data were collected through a structured questionnaire and clinical oral examination.

History and clinical parameters noted from patients were categorized as follow: demographic data (age and sex), smoking habit (yes/no); presence of oral lesions (yes/no); lesion features (type, localization, size, presence of symptoms, single/multiple, whether the patient was aware of 
the presence of the lesion (if the patient thought that he/she may have a lesion this was recorded positive for awareness). All the oral white lesions were examined and recorded, frequencies were calculated.

Salivary flow rate: Samples from patients were collected at the day of examination by spitting method for 5 minutes (Navazesh and Kumar, 2008).

Salivary pH: We measured the $\mathrm{pH}$ of saliva after collection by utilizing the constricted range $\mathrm{pH}$ strip system (Merck). The technique was to simply apply one drop of the salivary fluid on the tested paper and when the change of the color occurs, it revealed the salivary $\mathrm{pH}$.

\section{Statistical analysis}

Data were fed to the computer and analyzed using IBM SPSS software package version 20.0. (Armonk, NY: IBM Corp). The KolmogorovSmirnov was used to verify the normality of distribution of variables; Comparisons between groups for categorical variables were assessed using Chi-square test (Fisher). Student t-test was used to compare two groups for normally distributed quantitative variables while Mann Whitney test was used to compare between two groups for not normally distributed quantitative variables. Significance of the obtained results was judged at the $5 \%$ level.

\section{RESULTS}

Demographic data: The present study was conducted on 114 subjects as presented in Table (1); 70 cases were males $(61.4 \%)$ and 44 cases were females $(38.6 \%)$. The mean \pm SD values for age were $51.9 \pm 9.3$ years old with a minimum of 30 and a maximum of 60 years old.

Dialysis data: as in Table (1), the mean \pm SD values for dialysis duration were $16.2 \pm 7.1$ months with a minimum of 6 months and a maximum of 24 months.
Medical history: Descriptive statistics for medical history of the study participants are presented in Table (1). The most prevalent medical condition was hypertension (85.1\%) followed by diabetes $(28.9 \%)$. The smoker's patients prevalence was $21.9 \%$.

Oral white lesions: Thirty three patients with ESRD put of the 114 ESRD patients (28.9\%) had oral white lesions manifestations. Distribution for these manifestations is presented in Table (2). The most prevalent oral white lesions were candida

TABLE (1): Distribution of the studied cases according to different parameters $(\mathrm{n}=$ 114)

\begin{tabular}{|c|c|}
\hline & No. $(\%)$ \\
\hline \multicolumn{2}{|l|}{ Age (years) } \\
\hline Mean \pm SD & $51.9 \pm 9.3$ \\
\hline Median (Min. - Max.) & $55(30-60)$ \\
\hline \multicolumn{2}{|l|}{ Sex } \\
\hline Male & $70(61.4 \%)$ \\
\hline Female & $44(38.6 \%)$ \\
\hline \multicolumn{2}{|l|}{ Medical history } \\
\hline Hypertension & $97(85.1 \%)$ \\
\hline Diabetes & $33(28.9 \%)$ \\
\hline Smoking & $25(21.9 \%)$ \\
\hline \multicolumn{2}{|l|}{ PH } \\
\hline Mean \pm SD & $7 \pm 0.8$ \\
\hline Median (Min. - Max.) & $7(6-9)$ \\
\hline \multicolumn{2}{|l|}{ Bl urea (mg/dl) } \\
\hline Mean \pm SD & $137.3 \pm 36.9$ \\
\hline Median (Min. - Max.) & $137.5(59-271)$ \\
\hline \multicolumn{2}{|l|}{ Flow rate/5min } \\
\hline Mean \pm SD & $1.7 \pm 1.2$ \\
\hline Median (Min. - Max.) & $1.5(0.1-5)$ \\
\hline \multicolumn{2}{|c|}{ Duration of dialysis (months) } \\
\hline Mean \pm SD & $16.2 \pm 7.1$ \\
\hline Median (Min. - Max.) & $18(6-24)$ \\
\hline \multicolumn{2}{|l|}{ Serum creatinine } \\
\hline Mean \pm SD & $5.7 \pm 1.6$ \\
\hline Median (Min. - Max.) & $5.7(2.4-9.7)$ \\
\hline
\end{tabular}

SD: Standard deviation 
(11.4\%) as in Figure (1), lichen planus or lichenoid lesions (10.5\%) as in Figure (2), and white keratosis $(6.1 \%)$, while the least oral white lesions were uremic stomatitis (2.6\%) and leukoplakia (2.6\%) as in Figure (3).

TABLE (2): Distribution of the studied cases according to prevalence of white lesions $(n=114)$

\begin{tabular}{cc}
\hline & No. (\%) \\
\hline Prevalence of white lesions & $\mathbf{3 3}(\mathbf{2 8 . 9 \% )}$ \\
Leukoplakia & $3(2.6 \%)$ \\
Lichen planus or lichenoid & $12(10.5 \%)$ \\
Keratosis & $7(6.1 \%)$ \\
Frictional & $6(5.3 \%)$ \\
Smokers & $1(0.9 \%)$ \\
Candida & $13(11.4 \%)$ \\
Uremic stomatitis & $3(2.6 \%)$ \\
\hline
\end{tabular}

TABLE (3): Relation between lichen planus or lichenoid with diabetes and hypertension $(\mathrm{n}=114)$

\begin{tabular}{|c|c|c|c|}
\hline \multicolumn{2}{|c|}{$\begin{array}{l}\text { Lichen planus or } \\
\text { lichenoid }\end{array}$} & \multirow{2}{*}{$\chi^{2}$} & \multirow{2}{*}{${ }^{\mathrm{FE}} \mathbf{p}$} \\
\hline $\begin{array}{c}\text { No } \\
(n=102)\end{array}$ & $\begin{array}{c}\text { Yes } \\
(\mathbf{n}=12)\end{array}$ & & \\
\hline
\end{tabular}

\section{Diabetes}

$\begin{array}{lllll}\text { No } & 79(77.5 \%) & 2(16.7 \%) & & \\ \text { Yes } & 23(22.5 \%) & 10(83.3 \%) & & \end{array}$

Hypertension

\begin{tabular}{|c|c|c|c|c|}
\hline No & $16(15.7 \%)$ & $1(8.3 \%)$ & \multirow{2}{*}{0.457} & \multirow{2}{*}{0.690} \\
\hline Yes & $86(84.3 \%)$ & $11(91.7 \%)$ & & \\
\hline & $<0.001^{*}$ & $<0.001^{*}$ & & \\
\hline
\end{tabular}

$\chi 2:$ Chi square test

FE: Fisher Exact

p: $p$ value for comparing between lichen planus or lichenoid with diabetes and hypertension

*: Statistically significant at $p \leq 0.05$

\section{Saliva assessment as described in Table (1):}

The mean $\pm \mathrm{SD}$ values for the salivary $\mathrm{pH}$ were $7 \pm 0.8$ with a minimum of 6 and a maximum of 9 . While the mean and SD values for salivary flow rate were $1.7 \pm 1.2 \mathrm{~mL} / 5 \mathrm{~min}$ with a minimum of 0.1 and a maximum of $5 \mathrm{~mL} / 5 \mathrm{~min}$.

Blood urea $(\mathbf{m g} / \mathbf{d L})$ : The mean $\pm \mathrm{SD}$ values for blood urea were $137.3 \pm 36.9 \mathrm{mg} / \mathrm{dL}$ with a minimum of 59 and a maximum of $271 \mathrm{mg} / \mathrm{dL}$ as shown in Table (1).

Creatinine level $(\mathbf{m g} / \mathbf{d L})$ : The mean $\pm \mathrm{SD}$ values for serum creatinine level were $5.7 \pm 1.6 \mathrm{mg} /$ $\mathrm{dL}$ with a minimum of 2.4 and a maximum of 9.7 $\mathrm{mg} / \mathrm{dL}$ as in Table (1).

In the current study we found that the prevalence of lichen planus or lichenoid lesions was statistically significantly higher in diabetic than non-diabetic patients $(83.3 \%$ compared to $16.7 \%)$, also the prevalence of lichen planus or lichenoid lesions was statistically significantly higher in hypertensive than non-hypertensive patients $(91.7 \%$ compared to $8.3 \%$ ) and this was presented in Table (3) and Figure (1).

Renal patients with oral candidiasis had statistically significant lower salivary $\mathrm{pH}$ and salivary flow rate $(6.1 \pm 0.3$ and $0.4 \pm 0.2)$ compared to those with no oral candidiasis $(7.1 \pm 0.8$ and $1.8 \pm$ 1.2) as described in Table (4) and Figure (2).

In the current study we found that ESRD patients with uremic stomatitis had statistically significant higher serum creatinine level and blood urea level $(9 \pm 0$ and $212.8 \pm 8.6)$ than those without uremic stomatitis (5.6 \pm 1.5 and $135.2 \pm 35.2)$ as described in Table (5). 
TABLE (4): Relation between candida and different parameters $(n=114)$

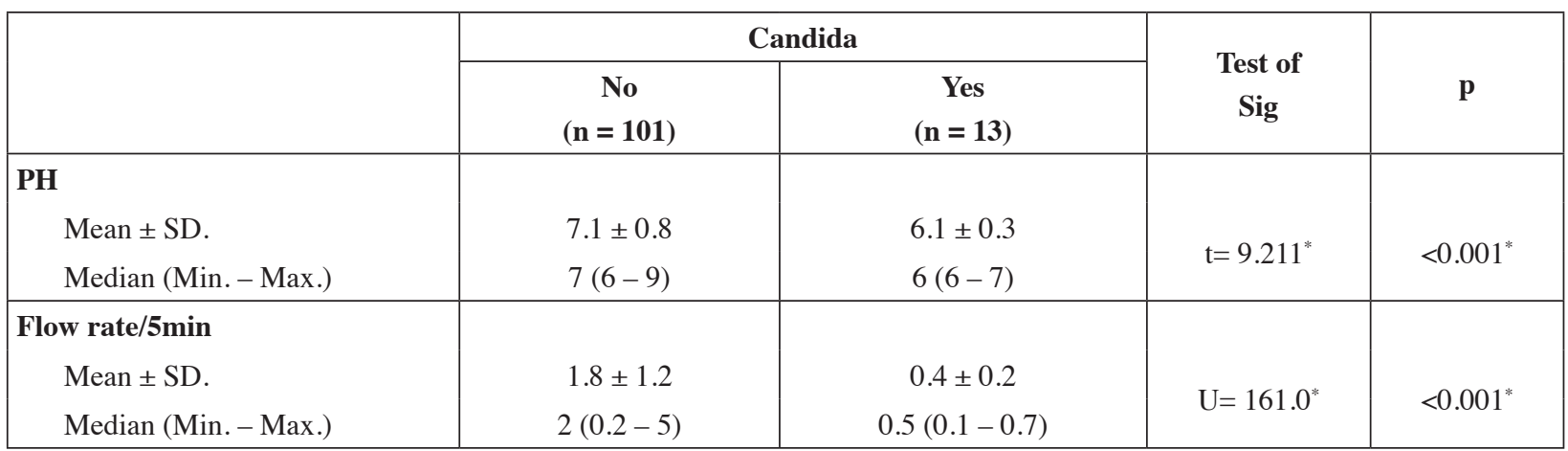

\section{SD: Standard deviation \\ 2: Chi square test \\ t: Student t-test \\ U: Mann Whitney test}

p: $p$ value for comparing between candida and different parameters

*: Statistically significant at $p \leq 0.05$

TABLE (5): Relation between uremic stomatitis with serum creatinine and Bl urea $(\mathrm{n}=114)$

\begin{tabular}{|c|c|c|c|c|}
\hline & \multicolumn{2}{|c|}{ Uremic Stomatitis } & \multirow[b]{2}{*}{$\mathbf{t}$} & \multirow[b]{2}{*}{$\mathbf{p}$} \\
\hline & $\begin{array}{c}\text { No } \\
(\mathrm{n}=\mathbf{1 1 1})\end{array}$ & $\begin{array}{c}\text { Yes } \\
(\mathbf{n}=\mathbf{3})\end{array}$ & & \\
\hline \multicolumn{5}{|l|}{ Serum creatinine } \\
\hline Mean $\pm \mathrm{SD}$ & $5.6 \pm 1.5$ & $9 \pm 0$ & & \\
\hline Median (Min. - Max.) & $5.7(2.4-9.7)$ & $9(9-9)$ & 12.900 & -0.001 \\
\hline \multicolumn{5}{|l|}{ Blood urea (mg/dl) } \\
\hline Mean \pm SD & $135.2 \pm 35.2$ & $212.8 \pm 8.6$ & $23017^{*}$ & SOPO1* \\
\hline Median (Min. - Max.) & $135(59-271)$ & $211.5(205-222)$ & 25.017 & $<0.001$ \\
\hline
\end{tabular}

SD: Standard deviation

t: Student t-test

p: $p$ value for comparing between uremic stomatitis with serum creatinine and Bl urea

*: Statistically significant at $p \leq 0.05$

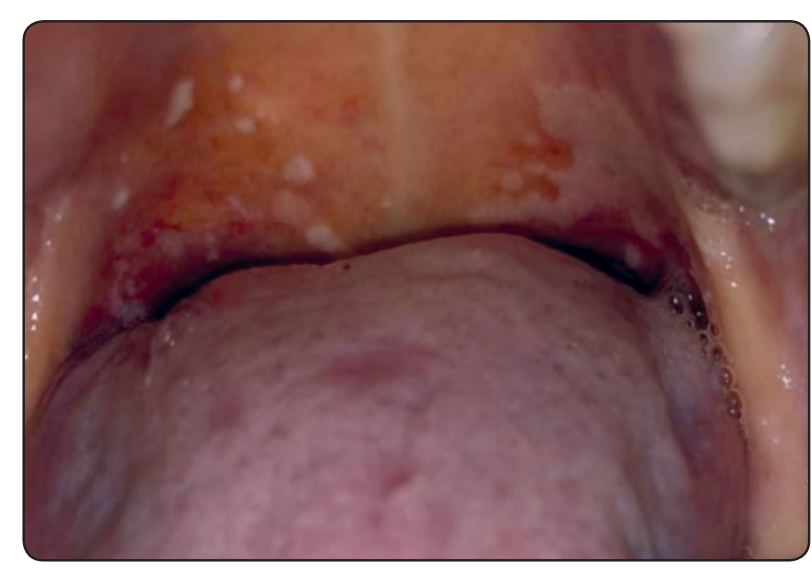

Fig. (1) Pseudomembranous candidiasis.

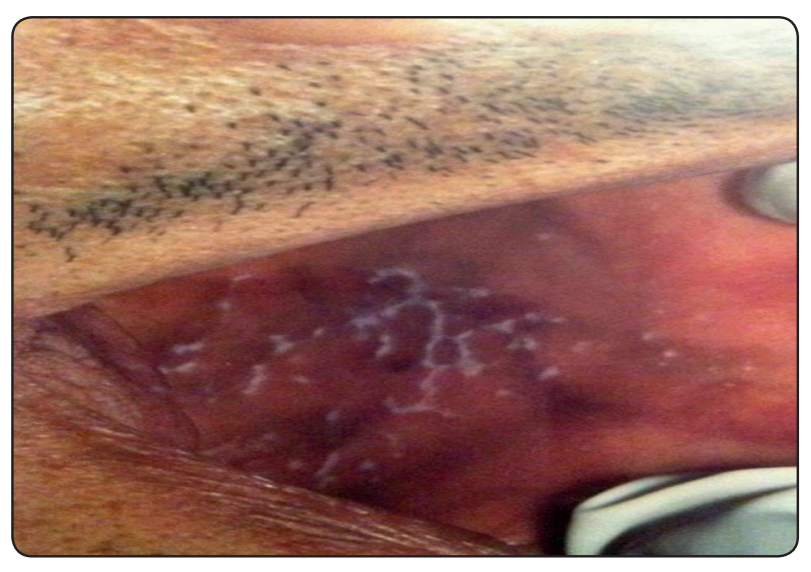

Fig. (2) Papular Lichen planus. 


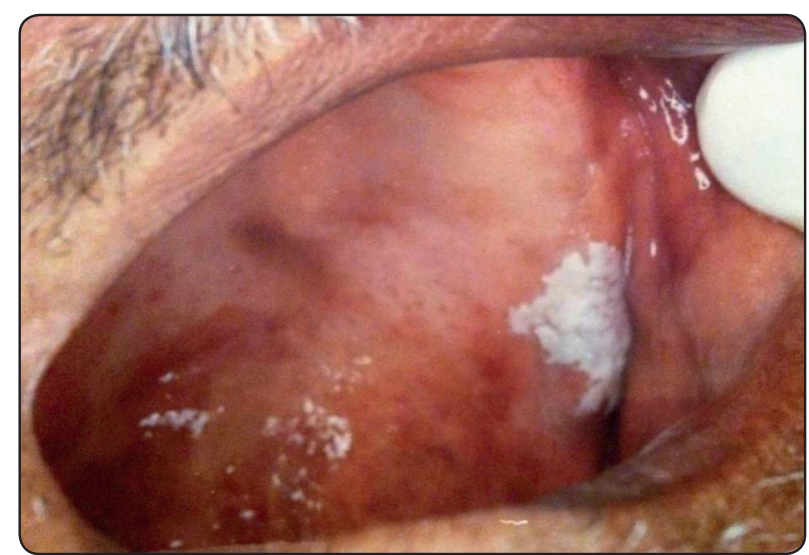

Fig. (3) Oral leukoplakia.

\section{DISCUSSION}

The general health of an individual is reliably reflected intra-orally as lesions (Somma et al.,2010). In accordance to the pathological process, lesions are categorized into five categories known as the 5 Is: inherent (hereditary or congenital, e.g., white spongy nevus), inflammatory (e.g., lichen planus, some geographic tongue variants), infection (e.g., oral candidal infection), iatrogenic (e.g., lichenoid reaction induced by drugs, frictional hyperkeratosis) and idiopathic (e.g., oral pre-malignant lesion or neoplasm) (Williams et al., 2008).

A prevalence of $28.9 \%$ of white lesions was found in our study among the 114 patients studied as a sample of end-stage renal disease (ESRD). To our knowledge, there are no earlier studies on prevalence of white lesions in such patients.

The present study detected $11.4 \%$ prevalence of oral candidiasis amongst ESRD patients; this was in accordance with previous studies that declared $5.7 \%$ to $37 \%$ prevalence of oral candidiasis in ESRD patients undergoing regular Hemodialysis HD (Galvada et al., 1999; Ziccardi et al., 1992). Our study outcomes were also in agreement with another study that reported $17.2 \%$ prevalence (la Rosa-García et al., 2006).

Also we reported that ESRD patients with oral candidiasis had significantly lower salivary ph and salivary flow rate compared to those with no oral candidiasis, as renal patients with salivary ph (7.1) had no candida, while renal patients with salivary ph (6.1) had candida.

The high prevalence of oral candidiasis in CKD patients may be attributed to the immune-suppression status caused by restricted diet, malnutrition, stress and immune-suppressive drugs (Oyetola et al., 2015). Those patients on HD protocol were deemed as immune-compromised due to suppression of cellinduced immunity and also granulocyte dysfunction induced by persistent uremia. The poor oral hygiene and xerostomia are most often etiological factors for oral infections in patients with CRF (Belazelkovska et al., 2013).

Saliva contains many antimicrobial defense mechanisms as $\operatorname{IgA}$, lysozymes and lactoferrins. Also, optimal salivary blood flow provides lubrication to mucosa and its buffering capacity ensures a physiological $\mathrm{pH}$ within the oral cavity (Shinozaki et al., 2012; Likar-Manookin et al., 2013). The salivary defense can be diminished in the CKD patients on HD, and oral micro-flora will then shift toward being predominantly Gram negative species which are more virulent (Kaushik et al., 2013).This might shed a light on an explanation for current study findings regarding the association between oral candidiasis and diminished salivary flow rate and reduced salivary $\mathrm{pH}$.

Uremic stomatitis was reported in 3 out of the 114 ESRD patients denoting a prevalence of $2.6 \%$. This was in accordance with an earlier study that detected a prevalence of 2\% (de la Rosa-García et al., 2006). Moreover, we found that ESRD patients with uremic stomatitis had significantly higher serum creatinine level and blood urea level than those without uremic stomatitis.

Uremic stomatitis lesions are represented intraorally by a localized or generalized erythematous areas covered by pseudo-membranous exudates that are liable to be removed, leaving either an intact or ulcerated mucosa. It is relatively uncommon, mostly 
of unknown etiology and manifest in advanced renal failure patients with blood urea nitrogen BUN levels exceeding $300 \mathrm{mg} / \mathrm{ml}$ (DeRossi and Cohen, 2008). Uremic stomatitis is ultimately diagnosed clinically, it resembles much other common oral pathology, and only few clinical aspects profit its differential diagnosis (Strippoli et al., 2013).

The possible etiological factors are tissue reactions to toxins or to uremic catablolites; irritant ammonia compound formed by oral bacterial flora hydrolyzing urea, and hemorrhagic diathesis, which is a popular manifestation of uremic syndromes (Ruospo et al., 2014).

Lichen planus or lichenoid reaction were reported in our study with a prevalence of 10.5 $\%$ and this was in contradiction to another study that reported a single lichen planus case out of 20 cases of CKD patients (Senthil et al., 2017). In the current study we found that the prevalence of lichen planus or lichenoid lesions were significantly higher in diabetic than non-diabetic patients, also the prevalence of lichen planus or lichenoid lesions were significantly higher in hypertensive than nonhypertensive patients.

Lichen planus is an immune mediated disease in which the immune system plays a pivotal role in its initiation, progression and even resolution (Tecklenborg et al., 2018). Generally HD sessions drive CKD patients to suffer from anxiety and depression. Anxiety and emotional factors are strongly influencing chronicity, manifestations and severity of lichen planus lesions. These are predominantly red, more symptomatic and more complex to be managed by clinician (Chaudhary, 2004).

Although oral lichen planus lesions may not have direct association with both diabetes mellitus and hypertension, those conditions could participate in oral lichen planus like lesions as a common outcome of medications taken by such patients. Also these patients experience severe mental stress and lichen planus could also be seen in them
(Bagewadi and Bhoweer, 2011). This could explain the association between lichenoid reaction lesions and both diabetes and hypertension encountered in our study ESRD patients.

\section{CONCLUSION}

Oral candidiasis (11.4\%), lichen planus or lichenoid reaction lesions (10.5\%) and oral keratotic lesions $(6.1 \%)$ were the most prevalent oral white lesions that we observed in the studied sample with ESRD. The present study found an association between the prevalence of oral candidiasis and the following (salivary $\mathrm{pH}$, salivary flow rate). Also an association between uremic stomatitis and the higher blood urea and higher serum creatinine level was found in our studied sample of the patients with ESRD. As a result, the underlying systemic disease may have an impact on dental health.

Meeting these patients' oral health needs is critical, as early detection and management of the oral lesions will enhance their oral health-related quality of life and also prevent future deterioration of their overall health. Setting up an integrated oral health intervention with general health care dental practitioners and nephrologists could accomplish this.

\section{RECOMMENDATIONS}

- A national oral health promotion campaign should be carried out targeting ESRD patients to raise their awareness of the need for dental visits (even if they are edentulous).

- Cooperation between nephrologists and dentists in the management of chronic renal patients to ensure optimal quality of life at all times.

- Early diagnosis by dental professionals is mandatory for early detection of oral white lesions especially those with a potentially malignant course.

- Further large scale studies are recommended to design and implement oral health programs for the ESRD patients in Egyptian population. 


\section{REFERENCES}

- Bagewadi A, Bhoweer AK.: Oral Lichen Planus and Its Association with Diabetes Mellitus and Hypertension.JIAOMR., 23(3):S300-303, 2011.

- Belazelkovska, Popovska, Spasovski, Radojkova-Nikolovska, Minovska, Belazelkoska, Mitic.: Oral Clinical Findings in Patients with Chronic Renal Failure. Balk J Stom., 17:37-43, 2013.

- Chaudhary S.: Psychosocial stressors in oral lichen planus. Aust Dent J., 49:192-5, 2004.

- Cooke BD.: Leukoplakia buccalis: An enigma. Proc R Soc Med., 68:337-41, 1975.

- Costantinides F, Castronovo G, Vettori E, Frattini C, Artero ML, Bevilacqua L, Berton F, Nicolin V and Di Lenard R.: Dental Care for Patients with End-Stage Renal Disease and Undergoing Hemodialysis. Int Journal of Dent., 9610892, 2018

- de la Rosa-García E, Mondragón-Padilla A, IrigoyenCamacho ME, Bustamante-Ramírez MA.: Oral lesions in a group of kidney transplant patients. Med Oral Patol Oral Cir Bucal., 10:196-204, 2005.

- DeRossi S, Cohen. Renal disease. In: Greenberg MS, Glick S, editors.: Burket's Oral Medicine. $11^{\text {th }}$ Ed. BC Decker; Hamiltlon., 363-383, 2008.

- Galvada C, Bagan J, Scully C et al.: Renal hemodialysis patients: oral,salivary,dental and periodontal findings in 105 adult cases. Oral Dis., 5:299-302, 1999.

- Hertel M, Schmidt-Westhausen AM, Strietzel FP.: Local, systemic, demographic, health-related factors influencing pathogenic yeast spectrum and antifungal drug administration frequency in oral candidiasis: a retrospective study. Clin Oral Investig., 20:1477-86, 2016.

- $\quad$ Kao CH, Hsieh JF, Tsai SC, Ho YJ, Chang HR.: Decreased salivary function in patients with end-stage renal disease requiring haemodialysis. Am J Kidney Diseases., 36: 1110-1114, 2000.

- Kaushik A, Reddy S, Umesh L, Devi BKY, Santana N and Rakesh N.: Oral and salivary changes among renal patients undergoing hemodialysis: A cross-sectional study. Indian J Nephrol., 23(2): 125-129, 2013.

- la Rosa-García E, Mondragón-Padilla A, Aranda-Romo S, Bustamante-Ramírez MA.: Oral mucosa symptoms, signs and lesions, in end stage renal disease and non-end stage renal disease diabetic patients. Med Oral Patol Oral Cir Bucal., 11:467-73, 2006.
- Leung KC, McMillan AS, Leung WK, Wong MC, Lau CS, Mok TM.: Oral health condition and saliva flow in southern Chinese with Sjögren's syndrome. Int Dent J., 54:159$65,2004$.

- Likar-Manookin K, Stewart C, Al-Hashimi I, Curtis W, Berg K, Cherian K, et al.: Prevalence of oral lesions of autoimmune etiology in patients with primary Sjogren's syndrome. Oral Dis., 6:598-603, 2013.

- Navazesh M, Kumar SK.: Measuring salivary flow challenging and oppourtunities. J Am Dent Assoc., 139: 355405, 2008.

- Oliveira MA, Carvalho LP, Gomes MdeS, Bacellar O, Barros TF, Carvalho EM.: Microbiological and immunological features of oral candidiasis. Microbiol Immunol., 51:713-9, 2007.

- Oyetola O, Foluso J, Gbemisola A, Olawami A, Abubarkar.: Oral findings in chronic kidney disease: implications for management in developing countries. BMC Oral Health.10.118615-015-0004, 2015.

- Payne TF.: Why are white lesions white?. Oral Surg., 40:652-6, 1975.

- Proctor R, Kumar N, Stein A, Moles D, and Porter S.: Oral and dental aspects of chronic renal failure. Journal of Dental Research., 84:199-208, 2005.

- Rahmati MA, Craig RG, Homel P, Kaysen GA, Levin NW.: Serum markers of periodontal disease status and inflammation in hemodialysis patients. Am J Kidney Dis., 40:983-989, 2002.

- Rodakowska E, Wilczyńska-Borawska M, Fryc J, Baginska J, Naumnik B.: Oral health-related quality of life in patients undergoing chronic hemodialysis. Patient Preference and Adherence., 12: 955-961, 2018.

- Ruospo M, Palmer SC, Craig JC, et al.: Prevalence and severity of oral disease in adults with chronic kidney disease: A systematic review of observational studies. Nephrol Dialys Transplant., 29:364-375, 2014.

- Senthil Asokan, Murali Narasimhan, Rajagopalan V.: Cutaneous Manifestations in Chronic Renal Failure Patients on Hemodialysis and medical management. Int J Res Dermatol.,2455-4529, 2017.

- Shinozaki S, Moriyama M, Hayashida JN, Tanaka A, Maehara $\mathrm{T}$, Ieda S, et al.: Close association between oral Candida species and oral mucosal disorders in patients with xerostomia. Oral Dis.,18:667-72, 2012. 
- $\quad$ Ship JA, Phelan J, Kerr AR.: Biology and pathology of the Oral Mucosa. In: Freedberg IM, Eisen AZ, Wolff K, Austen KF, Goldsmith LA, Katz SI, editors. Fitzpatrick's dermatology in general medicine.6th ed. Vol. 112. New York: McGraw-Hill pp. 1077-91, 2003.

- Somma F, Castagnola R, Bollino D, Marigo L.: Oral inflammatory process and general health. Part 1: The focal infection and the oral inflammatory lesion. Eur Rev Med Pharmacol Sci., 14:1085-95, 2010.

- Strippoli GF, Palmer SC, Ruospo M, et al.: Oral disease in adults treated with hemodialysis: Prevalence, predictors, and association with mortality and adverse cardiovascular events: The rationale and design of the ORAL Diseases in hemodialysis (ORAL-D) study, a prospective, multinational, longitudinal, observational, cohort study. BMC Nephrol., 14:90, 2013.
- Tecklenborg J, Clayton D, Siebert S, Coley S.M.: The role of the immune system in kidney disease. Clin Exp Immunol., 192(2): 142-150, 2018.

- Tong DC, Ferguson MM. A clinical approach to white patches in the mouth [internet].nzfp. Oct, pp., 334-9, 2002.

- Torres SR, Peixoto CB, Caldas DM, Silva EB, Akiti T, Nucci M, et al.: Relationship between salivary flow rates and Candida counts in subjects with xerostomia. Oral Surg Oral Med Oral Pathol Oral Radiol Endod., 93:149-154, 2002.

- Williams D, Lewis M.: Pathogenesis and treatment of oral candidosis. J Oral Microbiol., 3:1-11, 2011.

- Williams PM, Poh CF, Hovan AJ, Ng S, Rosin MP.: Evaluation of a suspicious oral mucosal lesion. J Can Dent Assoc., 74:275-80, 2008. 